\title{
Development of Rotational Intraperitoneal Pressurized Aerosol Chemotherapy to Enhance Drug Delivery into the Peritoneum
}

\section{Soo Jin Park}

Seoul National University College of Medicine

\section{Eun Ji Lee}

Seoul National University College of Medicine

Hee Su Lee

Seoul National University Graduate School Department of Biomedical Science

Junsik Kim

Seoul National University Graduate School Department of Biomedical Science

\section{Sunwoo Park}

Korea University College of Life Sciences and Biotechnology

\section{Jiyeon Ham}

Korea University School of Life Sciences and Biotechnology: Korea University College of Life Sciences and Biotechnology

\section{Jaehee Mun}

Seoul National University College of Medicine

\section{Haerin Paik}

Seoul National University College of Medicine

\section{Hyunji Lim}

Seoul National University College of Medicine

\section{Aeran Seol}

Seoul National University College of Medicine

\section{Ga Won Yim}

Dongguk University

\section{Seung-Hyuk Shim}

Konkuk University School of Medicine

\section{Beong-Cheol Kang}

Seoul National University College of Medicine

\section{Suk Joon Chang}

Ajou University School of Medicine and Graduate School of Medicine

\section{Whasun Lim}

Kookmin University 


\section{Gwonhwa Song}

Korea University School of Life Sciences and Biotechnology: Korea University College of Life Sciences and Biotechnology

\section{Jae Weon Kim}

Seoul National University College of Medicine

\section{Nara Lee}

CHA University

Jung Chan Lee

Seoul National University College of Medicine Hee Seung Kim ( $\nabla$ bboddi0311@gmail.com )

Seoul National University College of Medicine https://orcid.org/0000-0001-6876-8671

\section{Research}

Keywords: rotational intraperitoneal pressurized aerosol chemotherapy, doxorubicin, distribution, tissue concentrations, penetration depth, pharmacokinetics, peritoneal metastasis

Posted Date: February 26th, 2021

DOI: https://doi.org/10.21203/rs.3.rs-237091/v1

License: (c) (i) This work is licensed under a Creative Commons Attribution 4.0 International License. Read Full License

Version of Record: A version of this preprint was published at Drug Delivery on January 1st, 2021. See the published version at https://doi.org/10.1080/10717544.2021.1937382. 


\section{Abstract \\ Background}

Pressurized intraperitoneal aerosol chemotherapy (PIPAC) has been introduced as palliative therapy for treating peritoneal metastasis (PM) of solid tumors. However, restricted use in the limited countries and the uneven distribution and penetration in various regions of the peritoneal cavity ac as disadvantages of PIPAC. Thus, the KOrean Rotational Intraperitoneal pressurized Aerosol chemotherapy (KORIA) trial group developed rotational intraperitoneal pressurized aerosol chemotherapy (RIPAC) for enhancing drug delivery into the peritoneum to treat PM, and evaluated the drug distribution, tissue concentrations, penetration depth, pharmacokinetic properties, and toxicities after RIPAC with doxorubicin in pigs.

\section{Methods}

For delivering doxorubicin as aerosols, we used our prototype for PIPAC, which sprayed about $30-\mu \mathrm{m}$ sized droplets through the nozzle. The mean diameter of the sprayed region was $18.5 \mathrm{~cm}$, and the penetration depth ranged from 360 to $520 \mu \mathrm{m}$, comparable to the microinjection pump (Capnopen®; Capnomed, Villingendorf, Germany). For RIPAC, a conical pendulum motion device was added to PIPAC for rotating the nozzle. RIPAC and PIPAC were conducted using $150 \mathrm{ml}$ of $1 \%$ methylene blue to evaluate drug distribution and $3.5 \mathrm{mg}$ of doxorubicin in $50 \mathrm{ml}$ of $0.9 \% \mathrm{NaCl}$ to evaluate tissue concentration and penetration depth, pharmacokinetic properties, and toxicities. All agents were sprayed as aerosols via the nozzle with a velocity of $5 \mathrm{~km} / \mathrm{h}$ at a flow rate of $30 \mathrm{ml} / \mathrm{min}$ under a pressure of 7 bars, and capnoperitoneum of $12 \mathrm{mmHg}$ was maintained for 30 minutes. As a control, we conducted early postoperative intraperitoneal chemotherapy (EPIC) using $1 \%$ methylene blue solution with an infusion flow rate of $100 \mathrm{ml} / \mathrm{min}$ for 30 minutes and the drainage of $1 \mathrm{~L}$ every 10 minutes.

\section{Results}

RIPAC showed a wider distribution and stronger intensity than EPIC and PIPAC. Moreover, the tissue concentration and penetration depth of doxorubicin were higher in RIPAC than in PIPAC. In RIPAC, the pharmacokinetic properties reflected hemodynamic changes during capnoperitoneum, and there were no renal and hepatic toxicities related to RIPAC using doxorubicin.

\section{Conclusions}

RIPAC may have the potential to enhance drug delivery into the peritoneum compared to PIPAC.

\section{Background}


Peritoneal metastasis (PM) occurs in up to $60 \%$ of advanced or recurrent diseases of solid tumors [1-3], which leads to a poor expected median survival of fewer than 20 months despite various types of intravenous chemotherapy [4]. Specifically, intravenous chemotherapy shows little effect on improving the prognosis of patients with PM because of the poor blood supply to the peritoneal surface with low penetration into tumors, thereby preventing eradication [5]. As an alternative, intraperitoneal chemotherapy has been attempted to treat PM of solid tumors by the direct contact of chemotherapeutic agents to the tumors without reliance on the blood supply for overcoming the limitations of intravenous chemotherapy

In a specific way, early postoperative intraperitoneal chemotherapy (EPIC) and hyperthermic intraperitoneal chemotherapy (HIPEC) have been used immediately after maximal cytoreduction for treating PM of solid tumors. Before applying EPIC and HIPEC, maximal cytoreduction leaving residual tumors of less than $2.5 \mathrm{~mm}$ is important for effective drug delivery even with limited penetrations of 1-3 $\mathrm{mm}$ during intraperitoneal chemotherapy [6]. Moreover, hyperthermia can increase the penetration of chemotherapeutic agents and enhance drug sensitivity by impairing DNA repair, inducing apoptosis, and promoting the denaturation of proteins $[7,8]$. However, catheter-related complications and renal or hepatic toxicity reduce the treatment cycles to achieve an insufficient effect, and their effectiveness has not been demonstrated in some types of solid tumors and recurrent diseases [9-11].

Pressurized intraperitoneal aerosol chemotherapy (PIPAC) has been introduced as palliative therapy for treating PM in recurrent diseases $[12,13]$. It delivers chemotherapeutic agents as aerosols with a median diameter of $25 \mu \mathrm{m}$ under a pressure of $200 \mathrm{psi}$ made by a high-pressure injector [14]. In particular, PIPAC has the advantages that only $10 \%$ of the dose of the chemotherapeutic agents used in intravenous chemotherapy is sprayed diffusely throughout the peritoneal cavity with fewer toxicities, and the tissue concentration after PIPAC is maintained up to 200 times that achieved after intravenous chemotherapy by interrupting the venous circulation by capnoperitoneum of $12 \mathrm{mmHg}$ made using a laparoscopic system, thereby suppressing systemic excretion of the agents $[4,15]$.

Nevertheless, restricted use due to dissemination in only some European countries and the uneven distribution and penetration in various regions of the peritoneal cavity act as disadvantages of PIPAC [16]. To overcome these limitations of PIPAC, the KoRIA (Korean Rotational Intraperitoneal pressurized Aerosol chemotherapy) trial group developed rotational intraperitoneal pressurized aerosol chemotherapy (RIPAC) by adding a remote-controlled device for rotating the PIPAC nozzle [17], and this study showed preclinical evidence that RIPAC may improve drug delivery compared to PIPAC with fewer toxicities in pigs.

\section{Materials And Methods}

\section{Rotational intraperitoneal pressurized aerosol chemotherapy system}


For delivering doxorubicin as aerosols, we used our prototype for PIPAC, which sprayed approximately 30$\mu \mathrm{m}$ sized droplets through the nozzle with a velocity of $5 \mathrm{~km} / \mathrm{h}$ at a flow rate of $30 \mathrm{ml} / \mathrm{min}$ under a pressure of 7 bars equivalent to about $100 \mathrm{psi}$ [18]. The mean diameter of the sprayed region was 18.5 $\mathrm{cm}$, and the penetration depth ranged from 360 to $520 \mu \mathrm{m}$, comparable to previous studies using the microinjection pump (Capnopen ${ }^{\circledR}$; Capnomed, Villingendorf, Germany) $[19,20]$.

For RIPAC, we added a remote-controlled conical pendulum motion device to our prototype for PIPAC and rotated the nozzle to improve drug delivery. The conical pendulum motion device was composed of a DC motor (12V/1.5A, GM35A-3323, Motorbank, Seoul, South Korea), a 3-D printed rotational stick, two endstops (PCB-mounted End-stop switch, RepRap, England), and an Arduino Uno. We inserted the nozzle in a 3-D printed rotational stick and locked it with a screw. The angle between the nozzle and the vertical line was determined at 30 degrees by considering a spraying angle of 77.2 degrees. The rotational stick could not rotate in the same direction because the tube line connected between the nozzle and the syringe pump became tangled. Thus, the rotational stick moved clockwise, and when the rotating stick contacted the sensor of the rotating path, it moved counterclockwise to maintain repetitive rotation (Fig. 1) [17].

\section{Reagents}

We purchased 1\% methylene blue and doxorubicin from Sigma-Aldrich (St. Louis, MO, USA) for intraperitoneal chemotherapy. For analyzing the serum and tissue concentrations of doxorubicin, we purchased acetonitrile and methanol from Fisher Scientific (Waltham, MA, USA) and formic acid, acetic acid, and ammonium acetate from Sigma-Aldrich. We purchased $1.5 \mu \mathrm{g} / \mathrm{ml}$ 4, 6-diamidino-2-phenylindole (DAPI) from Sigma-Aldrich to evaluate the penetration depth of doxorubicin.

\section{Preparation}

This study was approved by the Institutional Animal Care and Use Committee (IACUC) of Seoul National University Hospital before study initiation (No. 18-0051-S1A0) and the investigators complied the protocol of IACUC. We purchased a total of 15 female pigs weighing 40 to $50 \mathrm{~kg}$ for this study, which were used to evaluate drug distribution $(n=6)$, tissue concentrations and penetration depth $(n=6)$, and pharmacokinetics and safety $(n=3)$ based on the types of intraperitoneal chemotherapy.

Before intraperitoneal chemotherapy, we applied capnoperitoneum by $\mathrm{CO}_{2}$ insufflation via a Veress needle to each pig, and then inserted two or three 12-mm bladeless trocars (Eagleport $\circledast$; Dalim Medical Corp., Seoul, South Korea) along the midline of the abdomen, which was used as a passage for inserting the nebulizer and laparoscopic devices (KARL STORZ Endoscopy Korea CO., Ltd., Korea). After inserting the nozzle through the trocar directly down to the ileum, PIPAC and RIPAC were applied using $150 \mathrm{ml}$ of $1 \%$ methylene blue to evaluate drug distribution and $3.5 \mathrm{mg}$ of doxorubicin in $50 \mathrm{ml}$ of $0.9 \% \mathrm{NaCl}$ to evaluate pharmacokinetics, tissue concentrations, and toxicities. After $1 \%$ methylene blue and doxorubicin solutions were aerosolized via the nozzle with a velocity of $5 \mathrm{~km} / \mathrm{h}$ at a flow rate of 30 $\mathrm{ml} / \mathrm{min}$ under a pressure of 7 bars, capnoperitoneum of $12 \mathrm{mmHg}$ was maintained for 30 minutes (Supplementary Videos 1 and 2). 


\section{Drug distribution}

With PIPAC and RIPAC in each of two pigs, we performed EPIC using $1 \%$ methylene blue in an additional two pigs as controls. During EPIC, $1 \%$ methylene blue solution was infused at a flow rate of $100 \mathrm{ml} / \mathrm{min}$ for 30 minutes, and $1 \mathrm{~L}$ of the solution was drained every 10 minutes. Thereafter, the pigs were euthanized and the distribution and intensity of $1 \%$ methylene blue in the parietal and visceral peritoneum in the EPIC, PIPAC, and RIPAC pigs were compared with the naked eye.

\section{Tissue concentration and penetration depth}

We generated a modified Peritoneal Cancer Index (PCI) using the PCl for patients with PM [21]. The modified PCl included nine parietal regions, including the central, right upper, epigastrium, left upper, left flank, left lower, pelvis, right lower, and right flank regions, and three visceral regions, which included the ileal, jejunal, and gastric regions (Fig. 2). According to the modified PCl, we obtained two specimens of $2 \times 2 \mathrm{~cm}$-sized peritoneal tissue from each region of six pigs after PIPAC and RIPAC.

For tissue concentrations, all tissue specimens were stored at $-80{ }^{\circ} \mathrm{C}$ and homogenized with a solvent consisting of a 1:1 mixture of methanol and 1\% acetic acid equivalents to twice the weight of the tissue specimens. Then, the homogenized tissues were mixed with $1 \mathrm{ml}$ of ethanol and vortexed for 30 minutes, and held overnight in a refrigerator. After that, the mixture was centrifuged at 14,000 rpm for 10 minutes, and the supernatants were dried in a SpeedVac for 180 minutes at $45^{\circ} \mathrm{C}$. The samples were reconstituted to $50 \mu \mathrm{l}$, vortexed with $150 \mu \mathrm{l}$ of acetonitrile with $50 \mathrm{ng} / \mathrm{ml}$ of daunorubicin as the internal standard for 30 seconds, and centrifuged at 13,000 rpm for 5 minutes The supernatant $(5 \mu \mathrm{l})$ was injected into HPLC for analysis.

To investigate the penetration depth of doxorubicin, we rinsed all tissue specimens with $0.9 \% \mathrm{NaCl}$ solution to clean doxorubicin off the surface and then froze them in liquid nitrogen. We prepared cryosections with a thickness of $7 \mu \mathrm{m}$ from three different specimen areas and applied DAPI. Thereafter, we estimated the depth of concentrated diffusion (DCD) and the depth of maximal diffusion (DMD) of doxorubicin in 12 regions by confocal laser scanning microscopy using a Leica TCS SP8 (Leica Mikrosysteme $\mathrm{GmbH}$, Hessen, Germany) and compared them between the PIPAC and RIPAC treatments. In this study, we defined DCD as the distance between the luminal surface and the surface where positive doxorubicin staining was most accumulated, and DMD as the distance between the luminal surface and the innermost depth at which positive doxorubicin staining was visualized.

\section{Pharmacokinetics and toxicities}

For evaluating the pharmacokinetics of RIPAC using doxorubicin, we collected blood from three pigs a total of 11 times as follows: before RIPAC, after 15 minutes, after 30 minutes, after 45 minutes, after 1 hour, after 1.25 hours, after 1.5 hours, after 1.75 hours, after 2 hours, after 24 hours, and after 48 hours. Then, $50 \mu \mathrm{l}$ of serum and $100 \mu \mathrm{l}$ of $0.1 \%$ formic acid acetonitrile with $15 \mathrm{ng} / \mathrm{ml}$ of daunorubicin as the internal standard were vortexed for 30 minutes. The mixtures were centrifuged at $14,000 \mathrm{rpm}$ for 10 minutes, and $5 \mu$ l of the supernatants were injected into HPLC for analysis. 
To investigate renal and hepatic toxicities, we collected blood from three pigs a total of six times as follows: before RIPAC, immediately after RIPAC, and after one to four days. Aspartate aminotransferase (AST), alanine aminotransferase (ALT), gamma-glutamyl transpeptidase (GGT), bilirubin, alkaline phosphatase (ALP), creatinine, and C-reactive protein (CRP) were measured in the serum.

\section{Liquid chromatography and tandem mass spectrometry}

We analyzed the serum and tissue concentrations of doxorubicin by high-performance liquid chromatography (HPLC) using an Agilent 1260 Infinity (Agilent, Santa Clara, CA, USA), followed by tandem mass spectrometry (MS/MS) using API4000QTRAP (Applied Biosystems, Waltham, MA, USA). For the HPLC analysis, a Gemini $5 \mu \mathrm{m}$ C18, $50 \times 2.0 \mathrm{~mm}$ analytical column (Phenomenex, Torrance, CA, USA) was used. The mobile phase consisted of $5 \mathrm{mM}$ ammonium acetate and $0.1 \%$ acetic acid acetonitrile with a flow rate of $0.3 \mathrm{ml} / \mathrm{min}$ and a $25^{\circ} \mathrm{C}$ column temperature over 7.5 minutes.

The MS/MS was equipped with a positive ionization mode with Turbo Spray, and multiple reaction monitoring was used for quantification. The nebulizer and desolvation gas pressure was 50 psi, both using nitrogen. MS/MS was conducted under a needle voltage of $5000 \mathrm{~V}$ and a set temperature of 400 ${ }^{\circ} \mathrm{C}$. The acquisition delay was 0 seconds with a pause time of $5 \mathrm{msec}$.

\section{Statistical analysis}

We performed a pharmacokinetic study for RIPAC with doxorubicin, based on a non-compartmental model using $\mathrm{R}$ software for pharmacokinetic analysis. To characterize the pharmacokinetic analysis, the peak serum concentration $\left(\mathrm{C}_{\max }, \mathrm{ng} / \mathrm{ml}\right)$ and the time to the peak serum concentration $\left(T_{\text {max }}\right.$, hour) were identified. Then, the area under the curve (AUC, $\mathrm{ng} / \mathrm{ml} \times$ hour) of the individual pharmacokinetic curve was calculated using the linear trapezoidal rule from zero to the time of the last observed positive concentration. The continuous variables were analyzed by the Kruskal-Wallis test and the Mann-Whitney $U$ test with the Bonferroni correction in SPSS version 22 software (IBM Corp., Armonk, NY, USA, RRID:SCR_002865). In this study, a significant P-value was defined as $\mathrm{P} \leq 0.05$ because of the nonparametric tests.

\section{Results}

RIPAC is more effective than EPIC and PIPAC for the distribution of methylene blue to the peritoneum

When we compared the distribution and intensity of $1 \%$ methylene blue staining in the EPIC, PIPAC, and RIPAC in the parietal peritoneum, the distribution was limited, and the intensity was weak after EPIC compared to PIPAC and RIPAC. Moreover, the distribution was wider, and the intensity was stronger after RIPAC than after PIPAC. Especially, 1\% methylene blue staining was observed in gravity-dependent regions after PIPAC, whereas all regions, regardless of gravity, were also strongly stained after RIPAC. Furthermore, the distribution was also the most comprehensive, and the intensity was also the most vigorous after RIPAC in the visceral peritoneum of the spleen, liver, gall bladder, stomach, small and large bowels, and mesentery (Fig. 3). 


\section{Tissue concentrations and penetration depth of doxorubicin are higher after RIPAC than after PIPAC}

When we compared the tissue concentrations of doxorubicin between PIPAC and RIPAC according to the modified $\mathrm{PCl}$, there were no differences in the tissue concentrations of doxorubicin in the left flank, pelvis, ileal, jejunal, and gastric regions, whereas the tissue concentrations of doxorubicin were higher after RIPAC than after PIPAC in the central, right upper, epigastrium, left upper, left lower, right lower, and right flank regions (Fig. 4 and Table 1).

Table 1

Comparison of tissue concentrations of doxorubicin between pressurized intraperitoneal aerosol chemotherapy (PIPAC) and rotational injection of pressurized intraperitoneal aerosol chemotherapy (RIPAC)

\begin{tabular}{|llll|}
\hline & PIPAC & RIPAC & P value \\
\hline Central $(\mathrm{ng} / \mathrm{ml})$ & $448.1(445.5,469)$ & $729(663.1,888.3)$ & 0.05 \\
\hline Right upper $(\mathrm{ng} / \mathrm{ml})$ & $1240(1113.9,1473.6)$ & $2124.8(1862,2277)$ & 0.05 \\
\hline Epigastrium $(\mathrm{ng} / \mathrm{ml})$ & $819.6(723.6,988.7)$ & $1860.9(1143,1910.5)$ & 0.05 \\
\hline Left upper $(\mathrm{ng} / \mathrm{ml})$ & $217.3(214.3,381.8)$ & $643.7(496,687.4)$ & 0.05 \\
\hline Left flank $(\mathrm{ng} / \mathrm{ml})$ & $912.5(752.8,944)$ & $916.2(753.5,1394)$ & 0.51 \\
\hline Left lower $(\mathrm{ng} / \mathrm{ml})$ & $189.6(183.4,213)$ & $651.6(378.2,747)$ & 0.05 \\
\hline Pelvis $(\mathrm{ng} / \mathrm{ml})$ & $213(203.5,406.5)$ & $434(364,678)$ & 0.13 \\
\hline Right lower $(\mathrm{ng} / \mathrm{ml})$ & $341.4(266.1,411.5)$ & $541(465,885.9)$ & 0.05 \\
\hline Right flank $(\mathrm{ng} / \mathrm{ml})$ & $161.7(141.4,266.1)$ & $373.5(331,460.8)$ & 0.05 \\
\hline lleal $(\mathrm{ng} / \mathrm{ml})$ & $187(111.4,291.5)$ & $216.7(212.6,551.1)$ & 0.28 \\
\hline Jejunal $(\mathrm{ng} / \mathrm{ml})$ & $21.2(8.1,24.4)$ & $16.5(8.6,16.6)$ & 0.51 \\
\hline Gastric $(\mathrm{ng} / \mathrm{ml})$ & $9.3(7.3,19)$ & $6.4(5.9,10.3)$ & 0.28 \\
\hline All values were shown as median and range $(\mathrm{ng} / \mathrm{ml})$. & \\
\hline
\end{tabular}

Figure 5 depicts the comparison of the penetration depth of doxorubicin between PIPAC and RIPAC. In terms of the penetration depth of doxorubicin, the DCD was higher after RIPAC than after PIPAC in the central, right upper, epigastrium, left upper, left flank, left lower, pelvis, right lower, and right flank regions. DMD was also higher after RIPAC than after PIPAC in the central, right upper, epigastrium, left flank, left lower, pelvis, right lower, and right flank regions. However, doxorubicin did not penetrate the peritoneum of the ileal, jejunal, and gastric areas in either the PIPAC or RIPAC pigs. Only mucosal doxorubicin staining without penetration into the peritoneum was observed (Fig. 6 and Table 2). 
Table 2

Comparison of the depth of concentrated diffusion (DCD) and depth of maximal diffusion (DMD) of doxorubicin between pressurized intraperitoneal aerosol chemotherapy (PIPAC) and rotational injection of pressurized intraperitoneal aerosol chemotherapy (RIPAC) according to the modified Peritoneal Cancer Index

\begin{tabular}{|c|c|c|c|c|c|c|}
\hline \multirow[t]{2}{*}{ Properties } & \multicolumn{3}{|c|}{ Depth of concentrated diffusion } & \multicolumn{3}{|c|}{ Depth of maximal diffusion } \\
\hline & PIPAC & RIPAC & $\begin{array}{l}P \\
\text { value }\end{array}$ & PIPAC & RIPAC & $\begin{array}{l}P \\
\text { value }\end{array}$ \\
\hline $\begin{array}{l}\text { Central } \\
(\mathrm{ng} / \mathrm{ml})\end{array}$ & $\begin{array}{l}116.9(111.3, \\
118.3)\end{array}$ & $\begin{array}{l}\text { 183.7 (180.1, } \\
\text { 190.2) }\end{array}$ & 0.05 & $\begin{array}{l}224.1(203.2, \\
229.1)\end{array}$ & $\begin{array}{l}338.4(332.5 \\
342.3)\end{array}$ & 0.05 \\
\hline $\begin{array}{l}\text { Right upper } \\
\text { (ng/ml) }\end{array}$ & $\begin{array}{l}223.2(221.8 \\
230.1)\end{array}$ & $\begin{array}{l}267.4(261.9 \\
269)\end{array}$ & 0.05 & $\begin{array}{l}250.5(242.3 \\
259.4)\end{array}$ & $\begin{array}{l}\text { 409.1 (401.8, } \\
412.9)\end{array}$ & 0.05 \\
\hline $\begin{array}{l}\text { Epigastrium } \\
(\mathrm{ng} / \mathrm{ml})\end{array}$ & $\begin{array}{l}240.1(233.9 \\
241.7)\end{array}$ & $\begin{array}{l}349.6(338.7 \\
352.7)\end{array}$ & 0.05 & $\begin{array}{l}322.1(308.6 \\
329.7)\end{array}$ & $\begin{array}{l}551.2(532.4 \\
563.2)\end{array}$ & 0.05 \\
\hline $\begin{array}{l}\text { Left upper } \\
\text { (ng/ml) }\end{array}$ & $\begin{array}{l}\text { 196.3 (192.6 } \\
200.3)\end{array}$ & $\begin{array}{l}232.5(228.6 \\
236.4)\end{array}$ & 0.05 & $\begin{array}{l}280.3(276.3 \\
295)\end{array}$ & $\begin{array}{l}\text { 291.2 (287.3, } \\
302.3)\end{array}$ & 0.28 \\
\hline $\begin{array}{l}\text { Left flank } \\
\text { (ng/ml) }\end{array}$ & $\begin{array}{l}137.6(135.9 \\
140.2)\end{array}$ & $\begin{array}{l}274.9(262.4, \\
283.4)\end{array}$ & 0.05 & $\begin{array}{l}362.4(358.6 \\
370.2)\end{array}$ & $\begin{array}{l}467.3(450.8 \\
470.1)\end{array}$ & 0.05 \\
\hline $\begin{array}{l}\text { Left lower } \\
\text { (ng/ml) }\end{array}$ & $\begin{array}{l}190.7(188, \\
191)\end{array}$ & $\begin{array}{l}392.7(389.7 \\
395.6)\end{array}$ & 0.05 & $\begin{array}{l}345.9 \text { (343.1, } \\
352.5)\end{array}$ & $\begin{array}{l}482.9(476.3 \\
499.4)\end{array}$ & 0.05 \\
\hline Pelvis (ng/ml) & $\begin{array}{l}\text { 190.3 (182, } \\
192.7)\end{array}$ & $\begin{array}{l}313.2(300.7 \\
320.9)\end{array}$ & 0.05 & $\begin{array}{l}278.9(266.2 \\
283.8)\end{array}$ & $\begin{array}{l}480.8(477.7 \\
482.3)\end{array}$ & 0.05 \\
\hline $\begin{array}{l}\text { Right lower } \\
\text { (ng/ml) }\end{array}$ & $\begin{array}{l}193.4(186.8 \\
197.7)\end{array}$ & $\begin{array}{l}289.3(286.7 \\
290.3)\end{array}$ & 0.05 & $\begin{array}{l}390.7(387.9 \\
397)\end{array}$ & $\begin{array}{l}390.6(489.7 \\
495.8)\end{array}$ & 0.05 \\
\hline $\begin{array}{l}\text { Right flank } \\
\text { (ng/ml) }\end{array}$ & $\begin{array}{l}140.2(136.9 \\
147.9)\end{array}$ & $\begin{array}{l}243.8(234.9 \\
253.2)\end{array}$ & 0.05 & $\begin{array}{l}289.4(279.3 \\
304)\end{array}$ & $\begin{array}{l}403.2(396.2, \\
413.2)\end{array}$ & 0.05 \\
\hline Ileal (ng/ml) & 0 & 0 & 1.00 & 0 & 0 & 1.00 \\
\hline $\begin{array}{l}\text { Jejunal } \\
\text { (ng/ml) }\end{array}$ & 0 & 0 & 1.00 & 0 & 0 & 1.00 \\
\hline $\begin{array}{l}\text { Gastric } \\
\text { (ng/ml) }\end{array}$ & 0 & 0 & 1.00 & 0 & 0 & 1.00 \\
\hline
\end{tabular}

\section{Pharmacokinetics of RIPAC using doxorubicin}

The time-dependent serum concentrations and pharmacokinetic properties of doxorubicin used in RIPAC are depicted in Table 3. The mean values of $C_{\max }, A U C$, and $T_{\max }$ were $23.02 \mathrm{ng} / \mathrm{ml}, 20.9 \mathrm{ng} / \mathrm{ml} \times$ hour, and 0.25 hour, respectively. All pigs showed a similar pharmacokinetic property pattern, in which the serum concentrations of doxorubicin reached a peak after 15 minutes, decreased after 30 minutes, increased again after 45 minutes, and decreased over 48 hours (Fig. 7 and Table 3). 
Table 3

Time-dependent serum concentrations and pharmacokinetic properties of doxorubicin used in rotational intraperitoneal pressurized aerosol chemotherapy (RIPAC)

\begin{tabular}{|c|c|}
\hline Time & RIPAC \\
\hline Before RIPAC (median, range, ng/ml) & $0(0,0)$ \\
\hline After 15 minutes (median, range, $\mathrm{ng} / \mathrm{ml}$ ) & $23.06(21.8,24.2)$ \\
\hline After 30 minutes (median, range, $\mathrm{ng} / \mathrm{ml}$ ) & $13.31(12.94,14.9)$ \\
\hline After 45 minutes (median, range, $\mathrm{ng} / \mathrm{ml}$ ) & $16.75(16.7,17.54)$ \\
\hline After $1 \mathrm{hr}$ (median, range, ng/ml) & $10.48(10.2,13.63)$ \\
\hline After $1.25 \mathrm{hr}$ (median, range, $\mathrm{ng} / \mathrm{ml}$ ) & $7.89(7.26,8.96)$ \\
\hline After $1.5 \mathrm{hr}$ (median, range, $\mathrm{ng} / \mathrm{ml}$ ) & $5.25(4.38,5.56)$ \\
\hline After $1.75 \mathrm{hr}$ (median, range, $\mathrm{ng} / \mathrm{ml}$ ) & $3(2.95,3.24)$ \\
\hline After $2 \mathrm{hr}$ (median, range, ng/ml) & $3.75(3,3.9)$ \\
\hline After 24 hours (median, range, ng/ml) & $0(0,0.61)$ \\
\hline After 48 hours (median, range, ng/ml) & $0(0,0)$ \\
\hline $\mathrm{C}_{\max }($ mean, SD, CV, ng/ml) & $23.02,1.2,0.05$ \\
\hline $\mathrm{AUC}^{*}$ (mean, SD, CV, ng/ml×hr) & $20.9,21.81,0.66$ \\
\hline $\mathrm{T}_{\max }($ mean, $\mathrm{SD}, \mathrm{CV}, \mathrm{hr}$ ) & $0.25,0,0$ \\
\hline
\end{tabular}

Abbreviations: AUC, the area under the curve; $\mathrm{C}_{\max }$, the peak serum concentration; $\mathrm{CV}$, coefficient of variation; $S D$, standard deviation; $T_{\max }$, the time measurement to $C_{\max }$.

*AUC was calculated from the time zero to the time of the last positive concentrations.

\section{RIPAC using doxorubicin has no renal and hepatic toxicities}

Table 4 shows the renal and hepatic toxicities before and after RIPAC with doxorubicin. The results showed no differences in creatinine, bilirubin, ALP, AST, ALT, GGT, or CRP before RIPAC, immediately after RIPAC, or on days $1,2,3$, or 4 . 
Table 4

Comparison of toxicities related to rotational intraperitoneal pressurized aerosol chemotherapy (RIPAC) with doxorubicin

\begin{tabular}{|c|c|c|c|c|c|c|c|c|}
\hline \multirow[t]{2}{*}{ Parameters } & \multicolumn{8}{|c|}{ Measurement time } \\
\hline & $\begin{array}{l}\text { Before } \\
\text { RIPAC }\end{array}$ & $\begin{array}{l}\text { Immediately } \\
\text { after RIPAC }\end{array}$ & Day 1 & Day 2 & Day 3 & Day 4 & Day 5 & $\begin{array}{l}P \\
\text { value }\end{array}$ \\
\hline $\begin{array}{l}\text { Creatinine } \\
(\mathrm{mg} / \mathrm{dl})\end{array}$ & $\begin{array}{l}0.99 \\
(0.63 \\
1.17)\end{array}$ & $\begin{array}{l}1.01 \\
1.35)\end{array}$ & $\begin{array}{l}0.82 \\
(0.77 \\
1.17)\end{array}$ & $\begin{array}{l}0.78 \\
(0.73 \\
1.07)\end{array}$ & $\begin{array}{l}0.84 \\
(0.7, \\
1.03)\end{array}$ & $\begin{array}{l}0.85 \\
(0.66 \\
1.07)\end{array}$ & $\begin{array}{l}0.78 \\
(0.78 \\
1.16)\end{array}$ & 0.998 \\
\hline $\begin{array}{l}\text { Bilirubin } \\
(\mathrm{mg} / \mathrm{dl})\end{array}$ & $\begin{array}{l}0.09 \\
(0.02 \\
0.15)\end{array}$ & $\begin{array}{l}0.03(0.01 \\
0.15)\end{array}$ & $\begin{array}{l}0.05 \\
(0.04 \\
0.15)\end{array}$ & $\begin{array}{l}0.04 \\
(0.02, \\
0.15)\end{array}$ & $\begin{array}{l}0.04 \\
(0.02 \\
0.15)\end{array}$ & $\begin{array}{l}0.04 \\
(0.02 \\
0.15)\end{array}$ & $\begin{array}{l}0.06 \\
(0.03 \\
0.15)\end{array}$ & 0.974 \\
\hline ALP (IU/I) & $\begin{array}{l}88.4 \\
(58.9 \\
95)\end{array}$ & $\begin{array}{l}77.1(57, \\
88)\end{array}$ & $\begin{array}{l}68.6 \\
(52.1 \\
71.3)\end{array}$ & $\begin{array}{l}69.6 \\
(55.1 \\
83.3)^{\prime}\end{array}$ & $\begin{array}{l}69.6 \\
(51.3 \\
96.7)\end{array}$ & $\begin{array}{l}70.8 \\
(53.1 \\
90.7)\end{array}$ & $\begin{array}{l}67.1 \\
(51.4, \\
82.3)\end{array}$ & 0.983 \\
\hline AST (IU/I) & $\begin{array}{l}60(21 \\
69)\end{array}$ & $50(38,64,3)$ & $\begin{array}{l}83(31, \\
98)\end{array}$ & $\begin{array}{l}95(36 \\
122)\end{array}$ & $\begin{array}{l}69(20 \\
154)\end{array}$ & $\begin{array}{l}86(21 \\
97.1)\end{array}$ & $\begin{array}{l}83(38, \\
92.8)\end{array}$ & 0.978 \\
\hline ALT (IU/I) & $\begin{array}{l}37(24, \\
55)\end{array}$ & $37(23,54)$ & $\begin{array}{l}38(24, \\
38)\end{array}$ & $\begin{array}{l}45(22 \\
50)\end{array}$ & $\begin{array}{l}51(21, \\
55)\end{array}$ & $\begin{array}{l}50(21 \\
68)\end{array}$ & $\begin{array}{l}63(20, \\
64)\end{array}$ & 0.982 \\
\hline GGT (IU/I) & $\begin{array}{l}59(21 \\
76)\end{array}$ & $49(22,63)$ & $\begin{array}{l}53(26, \\
56)\end{array}$ & $\begin{array}{l}48(27, \\
59)\end{array}$ & $\begin{array}{l}54(25, \\
56)\end{array}$ & $\begin{array}{l}51(24 \\
64)\end{array}$ & $\begin{array}{l}55(25, \\
90)\end{array}$ & 0.995 \\
\hline $\operatorname{CRP}(g / l)$ & $\begin{array}{l}0.01(0 \\
0.01)\end{array}$ & $0(0,0.1)$ & $\begin{array}{l}0(0, \\
0.1)\end{array}$ & $\begin{array}{l}0.01 \\
(0.01 \\
0.1)\end{array}$ & $\begin{array}{l}0.01 \\
(0.01 \\
0.1)\end{array}$ & $\begin{array}{l}0.01(0 \\
0.1)\end{array}$ & $\begin{array}{l}0(0, \\
0.1)\end{array}$ & 0.888 \\
\hline \multicolumn{9}{|c|}{$\begin{array}{l}\text { Abbreviation: ALP, alkaline phosphatase; ALT, alanine aminotransferase; AST, aspartate } \\
\text { aminotransferase; CRP, C-reactive protein; GGT, gamma-glutamyl transferase. }\end{array}$} \\
\hline
\end{tabular}

\section{Discussion}

PIPAC has been suggested to be useful as palliative therapy for PM of recurrent or refractory solid tumors, which may lead to histologic regression, and thereby improve the quality of life [22-25]. Even if chemotherapeutic agents shown to be resistant in intravenous chemotherapy are used again in PIPAC, the agents may be absorbed into the peritoneal tumors by passive diffusion, which can be effective for treating PM by maintaining higher concentrations within tumor tissues while minimizing systemic absorption $[26,27]$. However, compartmentalization by inadequate exposure of the entire peritoneal cavity due to postoperative adhesion, individual differences in the three-dimensional structure of the peritoneal cavity, and aerosol delivery capacity limited by gravity can hinder homogeneous distribution and effective penetration of chemotherapeutic agents into the peritoneum during PIPAC. For enhancing drug delivery during PIPAC, the nozzle rotation can change the spray direction, thereby improving the homogeneous distribution of chemotherapeutic agents [28]. Thus, this study tried to provide preclinical evidence 
showing that RIPAC developed by the KoRIA trial group may enhance drug delivery compared to PIPAC with fewer toxicities.

First of all, RIPAC was superior to EPIC and PIPAC in terms of the distribution and intensity of the chemotherapeutic agents. Even though aerosols with a median diameter of $25 \mu \mathrm{m}$ are injected into the peritoneal cavity with a velocity of $60 \mathrm{~km} / \mathrm{hr}$ in PIPAC [29], RIPAC may spray droplets with a median diameter of $30 \mu \mathrm{m}$ with a velocity of $5 \mathrm{~km} / \mathrm{hr}$ under the same flow rate of $30 \mathrm{ml} / \mathrm{min}$ [18]. This means that the nozzle injection outlet may be larger in RIPAC than in PIPAC, which can reduce the turbulent flow of aerosols with a lower velocity in RIPAC [30]. Subsequently, RIPAC may make aerosols move based on the inertia created by the injection pressure, and deflections by the collisions may allow aerosols to move to various regions in the peritoneal cavity compared to PIPAC [31]. Additionally, the conical pendulum motion in RIPAC can contribute to the enhancement of drug delivery.

Moreover, the enhancement of drug delivery improved the tissue concentrations and penetration depth of doxorubicin in RIPAC despite the lower injection pressure of aerosols in RIPAC compared to PIPAC (101 vs. $200 \mathrm{psi}$ ). These findings mean that more droplets of the agent reached various regions in the peritoneal cavity. A previous ex vivo study supported these findings, where the penetration depth increased as the doxorubicin concentration increased [19].

In particular, it is important that the DCD was higher in RIPAC than in PIPAC because the area with a concentrated population of cells affected by doxorubicin can promote cytotoxic effects [18]. Moreover, the DMD after PIPAC in this study was similar to the value reported in a previous study $(\leq 400 \mu \mathrm{m}){ }^{28}$ and RIPAC showed a higher DMD than PIPAC $(\leq 500 \mu \mathrm{m})$ in most of the regions in the peritoneal cavity, indicating that RIPAC may be more advantageous for the passive diffusion of chemotherapeutic agents than PIPAC.

In terms of the pharmacokinetic properties of doxorubicin, the serum concentrations peaked after 15 minutes, decreased after 30 minutes, increased again after 45 minutes, and decreased over 48 hours. These pharmacokinetic properties of doxorubicin were different from those reported in a previous study where the serum concentrations of doxorubicin decreased after the peak was reached 30 minutes after PIPAC [12]. However, the pharmacokinetic changes in doxorubicin in this study seem to make more sense when we consider hemodynamic changes during laparoscopic surgery. During laparoscopic surgery, the compression of the inferior vena cava and the portal vein may lead to a decrease in venous return and an increase in systemic vascular resistance (SVR), which could decrease the systemic absorption of doxorubicin. However, subsequent changes in the endocrine system may decrease SVR, which could increase the systemic absorption of doxorubicin again [32]. A previous study reported that serum levels of vasopressin may decrease 30 minutes after capnoperitoneum, and thereby, SVR may decrease and cardiac output may increase, supporting the pharmacokinetic properties of doxorubicin after RIPAC in this study [33]. Furthermore, there were no renal and hepatic toxicities caused by RIPAC with doxorubicin consistent with relevant studies that showed a similar safety profile after PIPAC $[15,34,35]$. The results indicate that RIPAC can be safely conducted like PIPAC in a clinical setting. 
In contrast, we found no penetration of doxorubicin into the peritoneum of the ileal, jejunal, and gastric regions in either RIPAC or PIPAC. Although the penetration depth was highest in the small bowel located directly under the nozzle in a previous study [28], we found no penetration of doxorubicin into the peritoneum of the ileal region despite being located directly under the nozzle. Although the relevant evidence is not definitive, we hypothesized that differences in the histologic structures between the visceral and parietal peritoneum rather than the position of the nozzle could lead to the concentration distributions. When we consider that the penetration depth of RIPAC may range within $500 \mu \mathrm{m}$, we can expect that doxorubicin can penetrate soft extraperitoneal fat tissues beyond the parietal peritoneum [36], whereas penetration into the dense muscularis layer beyond the visceral peritoneum seems difficult [37, 38]. Our findings that the tissue concentrations of doxorubicin were lower in the visceral peritoneum than in the parietal peritoneum support this hypothesis, and lower tissue concentrations in the visceral peritoneum seemed to be related to the systemic absorption of doxorubicin in the mucosal layer instead of the direct penetration of doxorubicin into the peritoneum.

\section{Conclusions}

Conclusively, we developed RIPAC to enhance drug delivery into peritoneal tumors and reported preclinical evidence that RIPAC may improve drug distribution, tissue concentrations, and the penetration depth compared to PIPAC (Fig. 8). Moreover, the pharmacokinetic properties after RIPAC may be determined by hemodynamic changes during capnoperitoneum, and renal and hepatic toxicities were not seen in RIPAC, suggesting that RIPAC can be effectively and safely introduced into clinical settings. Nevertheless, whether improved drug delivery and penetration into the peritoneum by RIPAC may be more effective for treating PM should be proven in clinical trials.

\section{Abbreviations}

ALP: alkaline phosphatase; ALT: alanine aminotransferase; AST: aspartate aminotransferase; AUC: area under the curve; $\mathrm{C}_{\text {max }}$ : peak serum concentration; CRP: C-reactive protein; DAPI: 4',6-diamidino-2phenylindole; DCD: depth of concentrated diffusion; DMD: depth of maximal diffusion; EPIC: early postoperative intraperitoneal chemotherapy; GGT: gamma-glutamyl transpeptidase; HIPEC: hyperthermic intraperitoneal chemotherapy; HLPC: high-performance liquid chromatography; IACUC: Institutional Animal Care and Use Committee; KoRIA: Korean Rotational Intraperitoneal pressurized Aerosol chemotherapy; MS/MS: tandem mass spectrometry; PCl: Peritoneal Cancer Index; PIPAC; pressurized intraperitoneal aerosol chemotherapy; PM: peritoneal metastasis; RIPAC: rotational intraperitoneal pressurized aerosol chemotherapy; $T_{\max }$ : time to the peak serum concentration.

\section{Declarations}

\section{Ethics approval and consent to participate}


This study was approved by the Institutional Animal Care and Use Committee (IACUC) of Seoul National University Hospital before study initiation (No. 18-0051-S1A0) and the investigators complied the protocol of IACUC.

\section{Consent for publication}

This article has been approved by all authors for publication.

\section{Availability of data and materials}

The datasets generated/analyzed during the current study are available.

\section{Competing interests}

All authors have no conflicts of interest to declare.

\section{Funding}

This research was supported by grants from Seoul National University [Grant numbers, 800-20170249, 800-20180201, 800-20190437], and Seoul National University Hospital [Grant number 06-20173250].

\section{Authors' contributions}

HSK and JCL designed the current study, and SJP, EJL, HSL, JK, SP, JH, JM, HP, HL, AS, NL and HSK performed the experiments. SJP, GWY, SHS, WL, GS, NL, JCL and HSK performed the data analysis. SJP, BCK, SJC, JWK, JCL and HSK wrote the draft of the manuscript. All authors read and approved the final manuscript.

\section{Acknowledgements}

We deeply appreciate to Dalim Medical Corp. and Samyang Biopharmaceuticals Corp. for collaborative work.

\section{Patents}

SJP, EJL, HSL, JK, JCL and HSK have a Korean pending patent entitled "Rotational Injection of Pressurized System for Intraperitoneal Chemotherapy” (KR1020200011994).

\section{References}

1. Quere P, Facy O, Manfredi S, Jooste V, Faivre J, Lepage C, et al. Epidemiology, Management, and Survival of Peritoneal Carcinomatosis from Colorectal Cancer: A Population-Based Study. Dis Colon Rectum. 2015;58:743-752.

2. Heintz AP, Odicino F, Maisonneuve P, Quinn MA, Benedet JL, Creasman WT, et al. Carcinoma of the ovary. FIGO 26th Annual Report on the Results of Treatment in Gynecological Cancer. Int J Gynaecol 
Obstet. 2006;95 Suppl 1:S161-S192.

3. Yarema R, Ohorchak M, Hyrya P, Kovalchuk Y, Safiyan V, Karelin I, et al. Gastric cancer with peritoneal metastases: Efficiency of standard treatment methods. World J Gastrointest Oncol 2020;12:569-581.

4. Robella M, Vaira M, De Simone M. Safety and feasibility of pressurized intraperitoneal aerosol chemotherapy (PIPAC) associated with systemic chemotherapy: an innovative approach to treat peritoneal carcinomatosis. World J Surg Oncol. 2016;14:128.

5. Thadi A, Khalili M, Morano WF, Richard SD, Katz SC, Bowne WB. Early Investigations and Recent Advances in Intraperitoneal Immunotherapy for Peritoneal Metastasis. Vaccines (Basel) 2018;6:54.

6. Witkamp AJ, de Bree E, Van Goethem R, Zoetmulder FA. Rationale and techniques of intra-operative hyperthermic intraperitoneal chemotherapy. Cancer Treat Rev. 2001;27:365-374.

7. van de Vaart PJ, van der Vange N, Zoetmulder FA, van Goethem AR, van Tellingen O, ten Bokkel Huinink WW, et al. Intraperitoneal cisplatin with regional hyperthermia in advanced ovarian cancer: pharmacokinetics and cisplatin-DNA adduct formation in patients and ovarian cancer cell lines. Eur $\mathrm{J}$ Cancer. 1998;34:148-154.

8. Spratt JS, Adcock RA, Muskovin M, Sherrill W, McKeonwn J. Clinical delivery system for intraperitoneal hyperthermic chemotherapy. Cancer Res. 1980;40:256-260.

9. Klaver CEL, Wisselink DD, Punt CJA, Snaebjornsson P, Crezee J, Aalbers AGJ, et al. Adjuvant hyperthermic intraperitoneal chemotherapy in patients with locally advanced colon cancer (COLOPEC): a multicentre, open-label, randomised trial. Lancet Gastroenterol Hepatol. 2019;4:761770.

10. Ishigami H, Fujiwara Y, Fukushima R, Nashimoto A, Yabusaki H, Imano M, et al. Phase III Trial Comparing Intraperitoneal and Intravenous Paclitaxel Plus S-1 Versus Cisplatin Plus S-1 in Patients With Gastric Cancer With Peritoneal Metastasis: PHOENIX-GC Trial. J Clin Oncol. 2018;36:1922-1929.

11. Kim SI, Cho J, Lee EJ, Park S, Park SJ, Seol A, Lee N, et al. Selection of patients with ovarian cancer who may show survival benefit from hyperthermic intraperitoneal chemotherapy: A systematic review and meta-analysis. Medicine (Baltimore.) 2019;98:e18355.

12. Solass W, Kerb R, Murdter T, Giger-Pabst U, Strumberg D, Tempfer C, Zoeren J, et al. Intraperitoneal chemotherapy of peritoneal carcinomatosis using pressurized aerosol as an alternative to liquid solution: first evidence for efficacy. Ann Surg Oncol. 2014;21:553-559.

13. Grass F, Vuagniaux A, Teixeira-Farinha H, Lehmann K, Demartines N, Hübner M. Systematic review of pressurized intraperitoneal aerosol chemotherapy for the treatment of advanced peritoneal carcinomatosis. Br J Surg. 2017;104:669-678.

14. Solass W, Hetzel A, Nadiradze G, Sagynaliev E, Reymond MA. Description of a novel approach for intraperitoneal drug delivery and the related device. Surg Endosc. 2012;26:1849-1855.

15. Blanco A, Giger-Pabst U, Solass W, Zieren J, Reymond MA. Renal and hepatic toxicities after pressurized intraperitoneal aerosol chemotherapy (PIPAC). Ann Surg Oncol. 2013;20:2311-2316.

16. De Andrade JP, Warner SG, Fong Y. Treatment of metastatic colorectal cancer: innovations in surgical techniques. J Surg Oncol. 2019;119:653-659. 
17. Mun J, Park SJ, Kim HS. Rotational intraperitoneal pressurized aerosol chemotherapy in a porcine model. Gland Surg. 2020.

18. Lee HS, Kim J, Lee EJ, Park SJ, Mun J, Paik H, et al. Evaluation of a Novel Prototype for Pressurized Intraperitoneal Aerosol Chemotherapy. Cancers (Basel). 2020;12:633.

19. Khosrawipour V, Khosrawipour T, Falkenstein TA, Diaz-Carballo D, Förster E, Osma A, et al. Evaluating the Effect of Micropump ${ }^{\odot}$ Position, Internal Pressure and Doxorubicin Dosage on Efficacy of Pressurized Intra-peritoneal Aerosol Chemotherapy (PIPAC) in an Ex Vivo Model. Anticancer Res. 2016;36:4595-4600.

20. Gohler D, Khosrawipour V, Khosrawipour T, Diaz-Carballo D, Albert Falkenstein T, Zieren J, et al. Technical description of the microinjection pump $\left(\mathrm{MIP}^{\circledR}\right)$ and granulometric characterization of the aerosol applied for pressurized intraperitoneal aerosol chemotherapy (PIPAC). Surg Endosc. 2017;31:1778-1784.

21. Jacquet $P$, Sugarbaker PH. Clinical research methodologies in diagnosis and staging of patients with peritoneal carcinomatosis. Cancer Treat Res. 1996;82:359-374.

22. Horvath P, Beckert S, Struller F, et al. Pressurized intraperitoneal aerosol chemotherapy (PIPAC) for peritoneal metastases of pancreas and biliary tract cancer. Clin Exp Metastasis. 2018;35:635-640.

23. Alyami M, Bonnot PE, Mercier F, Laplace N, Villeneuve L, Passot G, et al. Pressurized intraperitoneal aerosol chemotherapy (PIPAC) for unresectable peritoneal metastasis from gastric cancer. Eur J Surg Oncol. 2020.

24. Ellebaek SB, Graversen M, Detlefsen S, Lundell L, Fristrup CW, Pfeiffer P, et al. Pressurized IntraPeritoneal Aerosol Chemotherapy (PIPAC)-directed treatment of peritoneal metastasis in endstage colo-rectal cancer patients. Pleura Peritoneum. 2020;5:20200109.

25. Tempfer CB, Winnekendonk G, Solass W, Horvat R, Giger-Pabst U, Zieren J, et al. Pressurized intraperitoneal aerosol chemotherapy in women with recurrent ovarian cancer: A phase 2 study. Gynecol Oncol. 2015;137:223-228.

26. Yan TD, Cao CQ, Munkholm-Larsen S. A pharmacological review on intraperitoneal chemotherapy for peritoneal malignancy. World J Gastrointest Oncol. 2010;2:109-116.

27. Alyami M, Hubner M, Grass F, Bakrin N, Villeneuve L, Laplace N, et al. Pressurised intraperitoneal aerosol chemotherapy: rationale, evidence, and potential indications. Lancet Oncol. 2019;20:e368e377.

28. Khosrawipour V, Khosrawipour T, Kern AJ, Osma A, Kabakci B, Diaz-Carballo D, et al. Distribution pattern and penetration depth of doxorubicin after pressurized intraperitoneal aerosol chemotherapy (PIPAC) in a postmortem swine model. J Cancer Res Clin Oncol. 2016;142:2275-2280.

29. Khosrawipour V, Khosrawipour T, Diaz-Carballo D, Förster E, Zieren J, Giger-Pabst U. Exploring the Spatial Drug Distribution Pattern of Pressurized Intraperitoneal Aerosol Chemotherapy (PIPAC). Ann Surg Oncol. 2016;23:1220-1224.

30. Klabunde RE. Cardiovascular physiology concenpts Seond edition. Lippincott Williams \& Wilkins. 2012. 
31. Flagan RC, Seinfeld JH. Fundamentals of air pollution engineering. Prentice-Hall, Inc., Englewood Cliffs, New Jersey. 1988.

32. Chui PT, Gin T, Oh TE. Anaesthesia for laparoscopic general surgery. Anaesth Intensive Care. 1993;21:163-171.

33. Joris JL, Chiche JD, Canivet JL, Jacquet NJ, Legros JJ, Lamy ML. Hemodynamic changes induced by laparoscopy and their endocrine correlates: effects of clonidine. J Am Coll Cardiol. 1998;32:13891396.

34. Solass W, Giger-Pabst U, Zieren J, Reymond MA. Pressurized intraperitoneal aerosol chemotherapy (PIPAC): occupational health and safety aspects. Ann Surg Oncol. 2013;20:3504-3511.

35. Ametsbichler P, Bohlandt A, Nowak D, Schierl R. Occupational exposure to cisplatin/oxaliplatin during Pressurized Intraperitoneal Aerosol Chemotherapy (PIPAC)? Eur J Surg Oncol. 2018;44:1793-1799.

36. Abrahams AC, Dendooven A, van der Veer JW, Wientjes R, Toorop RJ, Bleys RLA, et al. Direct Comparison of the Thickness Of The Parietal Peritoneum Using Peritoneal Biopsy and Ultrasonography of the Abdominal Wall in Patients Treated with Peritoneal Dialysis. Perit Dial Int. 2019;39:455-464.

37. van Baal JO, Van de Vijver KK, Nieuwland R, vsn Noorden CJF, van Driel WJ, Sturk A, et al. The histophysiology and pathophysiology of the peritoneum. Tissue Cell. 2017;49:95-105.

38. Isaza-Restrepo A, Martin-Saavedra JS, Velez-Leal JL, Vargas-Barato F, Riveros- Dueñas R. The Peritoneum: Beyond the Tissue - A Review. Front Physiol. 2018;9:738.

\section{Figures}

\section{Figure 1}

Schematic diagram of rotational intraperitoneal pressurized aerosol chemotherapy (RIPAC). (A) A highpressure injector to generate a pressure of 7 bars $(=101 \mathrm{psi}),(B)$ the conical pendulum motion device for rotating the nozzle during RIPAC, and (C) the spraying angle of 77.2 degrees. 


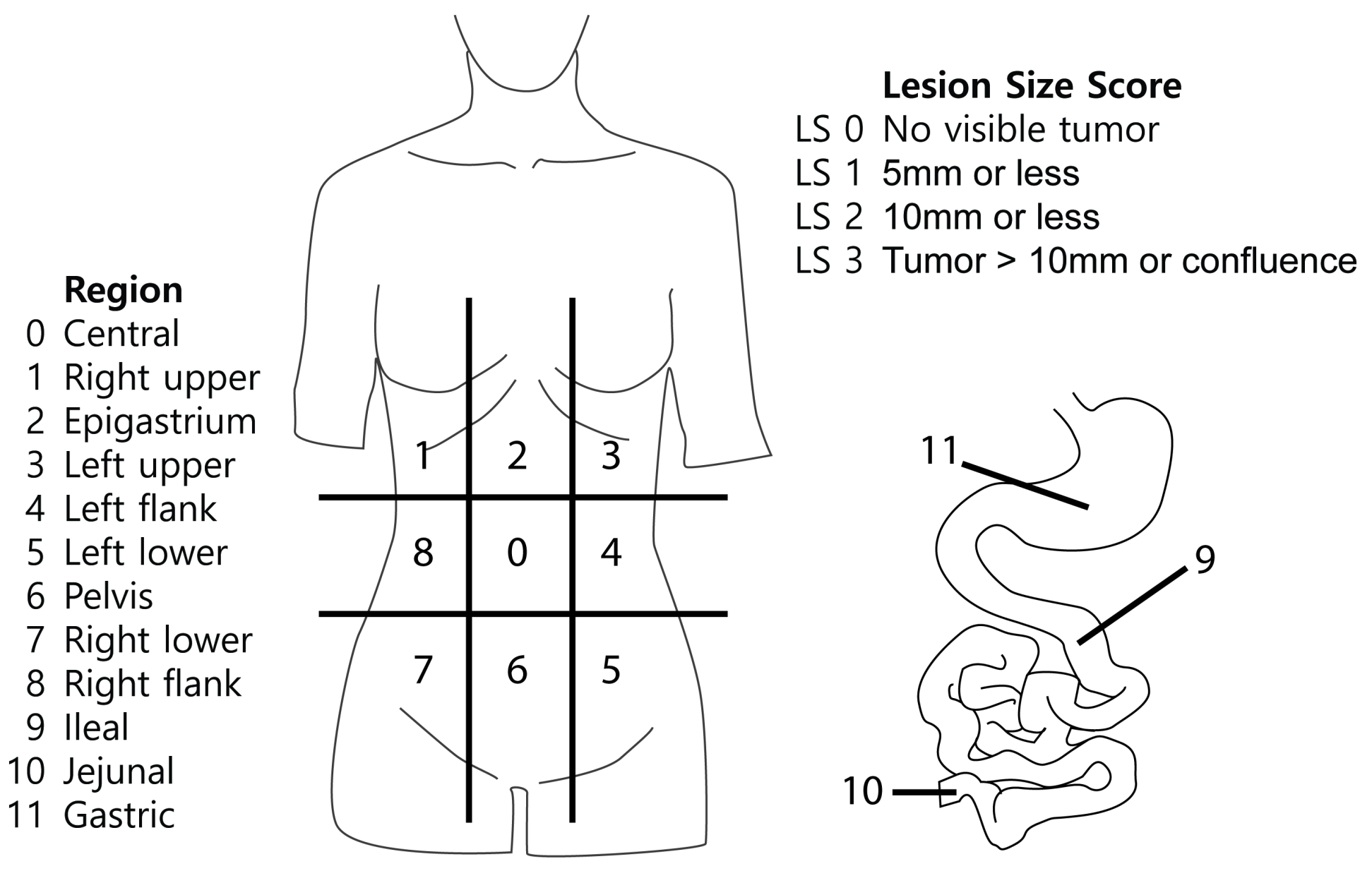

Figure 2

The modified Peritoneal Cancer Index (PCI) in a pig model 


\section{Figure 3}

Comparison of the distribution and intensity of $1 \%$ methylene blue staining in early postoperative intraperitoneal chemotherapy (EPIC), pressurized intraperitoneal aerosol chemotherapy (PIPAC), and rotational intraperitoneal pressurized aerosol chemotherapy (RIPAC) in (A) the parietal and (B) visceral peritoneum. 


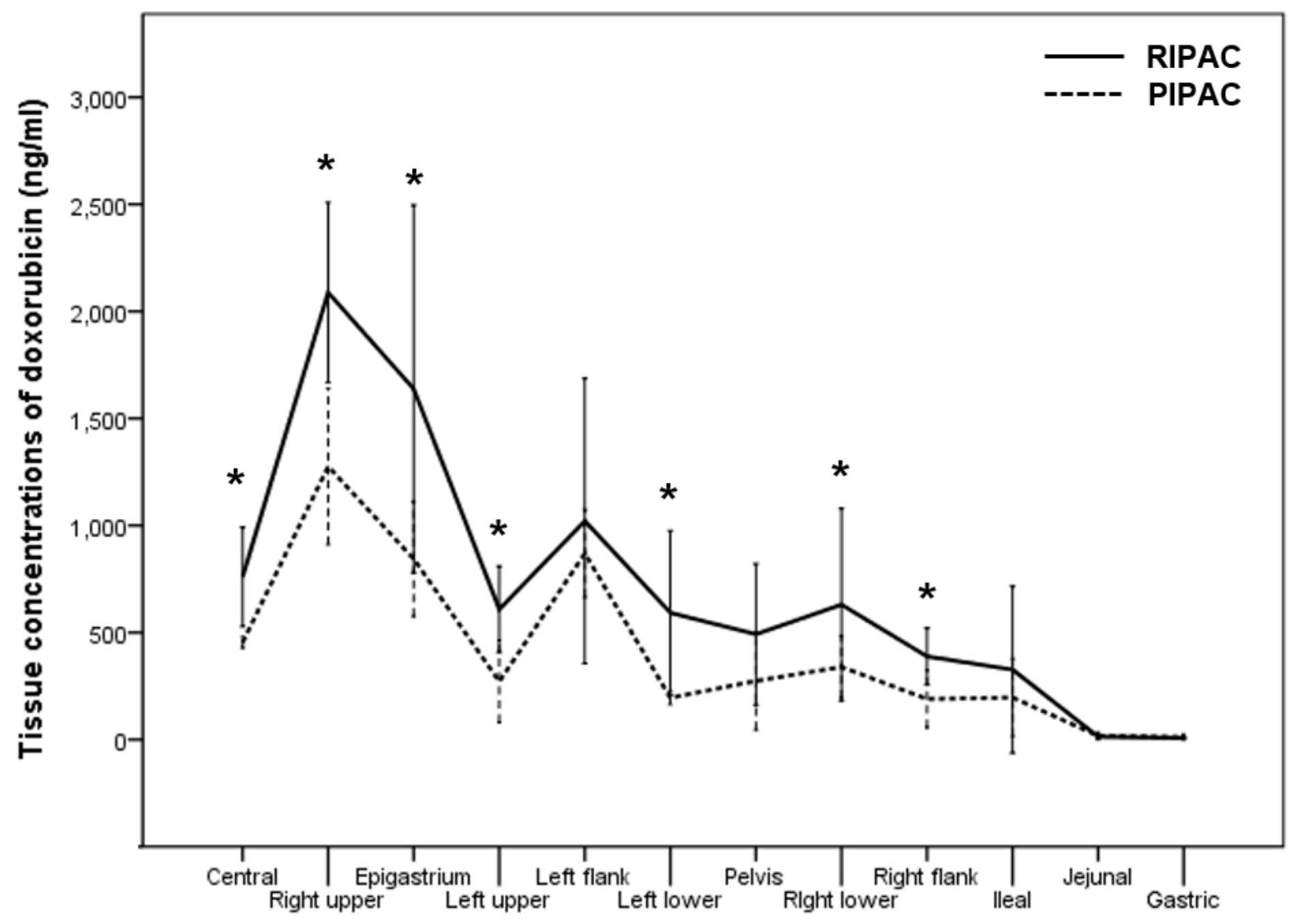

Figure 4

Comparison of tissue concentrations of doxorubicin between pressurized intraperitoneal aerosol chemotherapy (PIPAC) and rotational intraperitoneal pressurized aerosol chemotherapy (RIPAC) according to the modified Peritoneal Cancer Index ( $\left.{ }^{P} \leq 0.05\right)$. 


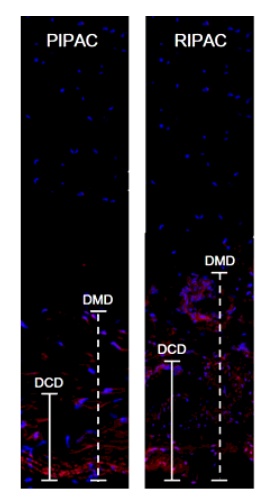

Central

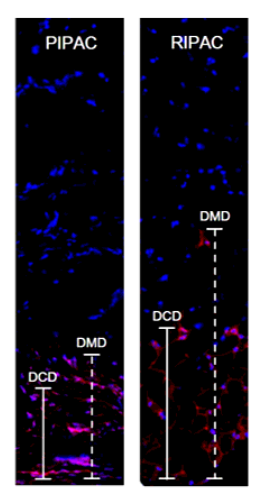

Pelvis

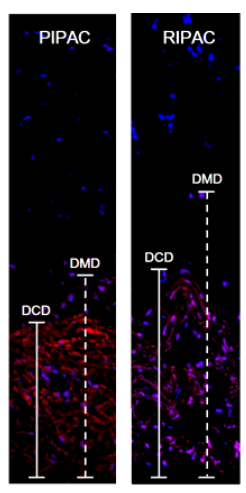

Right upper

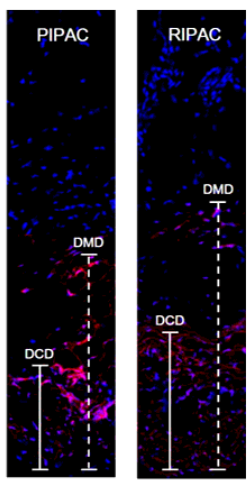

Right lower

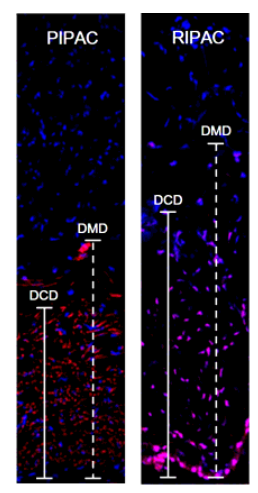

Epigastrium

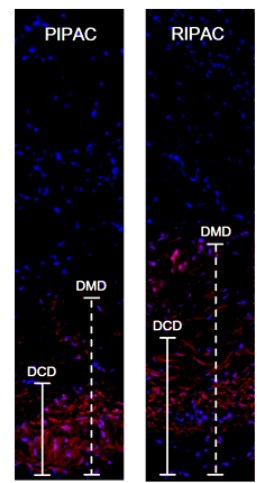

Right flank

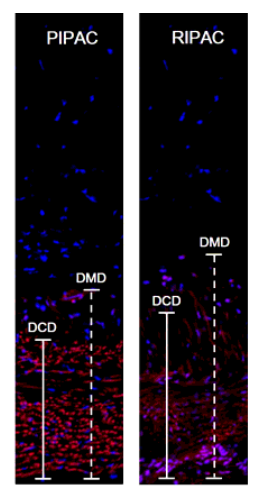

Left upper

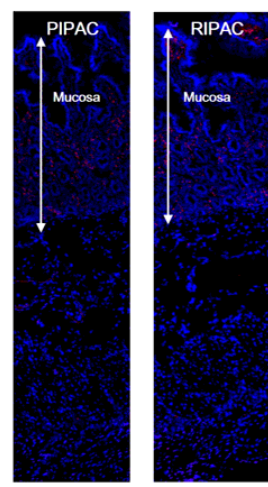

Ileal

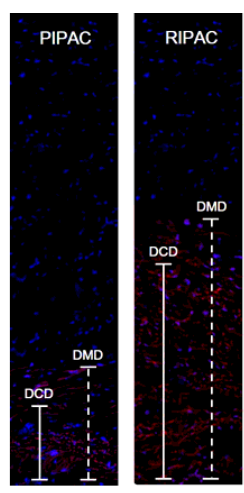

Left flank

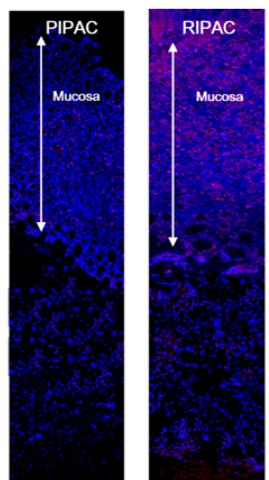

Jejunal

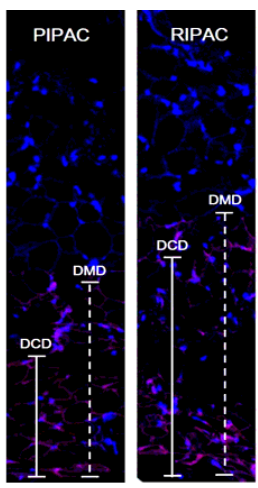

Left lower

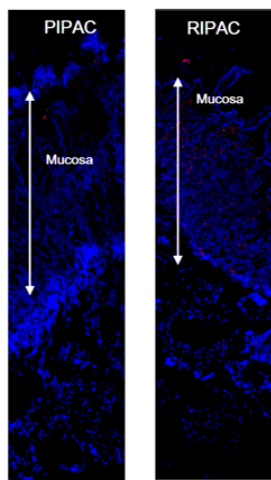

Gastric

Figure 5

The depth of concentrated diffusion (DCD) and the depth of maximal diffusion (DMD) using confocal laser scanning microscopy in pressurized intraperitoneal aerosol chemotherapy (PIPAC) and rotational intraperitoneal pressurized aerosol chemotherapy (RIPAC) according to the modified Peritoneal Cancer Index.

\section{Figure 6}

Comparison of the depth of concentrated diffusion (DCD) and the depth of maximal diffusion (DMD) between pressurized intraperitoneal aerosol chemotherapy (PIPAC) and rotational intraperitoneal pressurized aerosol chemotherapy (RIPAC) according to the modified Peritoneal Cancer Index ( $\left.{ }^{\star} P \leq 0.05\right)$.

\section{Figure 7}

The pharmacokinetic properties of doxorubicin after rotational intraperitoneal pressurized aerosol chemotherapy (RIPAC). (A) Individual data and (B) group data. 


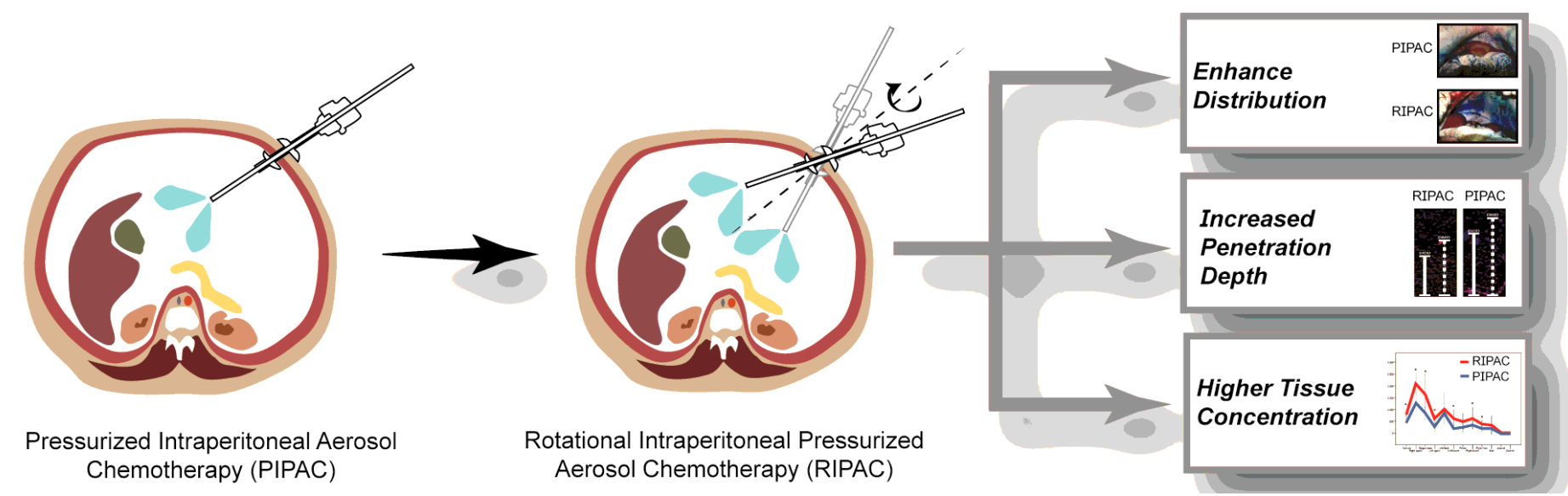

Figure 8

Schematic diagram of rotational intraperitoneal pressurized aerosol chemotherapy to enhance drug delivery into peritoneal tumors.

\section{Supplementary Files}

This is a list of supplementary files associated with this preprint. Click to download.

- SupplementaryVideo1.mp4

- SupplementaryVideo2.mp4 